$\mathrm{SAD} / \mathrm{JSR}$

Sosyoloji Araştırmaları Dergisi / Journal of Sociological Research

Cilt / Volume 21 Sayı / Number 2 (Ekim / October 2018) : (29-48)
Araştırma Makelesi / Research Article

Geliş Tarihi / Submited: 12.02.2018

Kabul Tarihi / Accepted: 11.04.2018

\title{
YAŞLILARIN SAĞLIK/HASTALIK DURUMLARININ TOPLUM SAĞLIĞI AÇISINDAN DEĞERLENDİRILMESİ
}

\author{
Dilek ASLAN ${ }^{1}$ \\ Ekin KOÇ \\ Merve ÇOLAKLAR ${ }^{3}$
}

\section{ÖZ}

"Bilgelik" ya da "ikinci çocukluk" olarak da adlandırılan yaşlılık dönemi bireylerde fizyolojik, psikolojik, sosyolojik vb. değişimler açısından önemli bir dönemdir. Bireylerin bu dönemi sağlıklı geçirebilmeleri için yaşamlarının çok erken evrelerinden itibaren önleyici davranışları içselleştirmeleri gerekir. Ülkemizde ve dünyada yaşlı birey sayısının artma eğiliminde olduğu dikkate alındığında, bütün toplumların yaşlılık konusunda sistem temelli değişiklikler yapma gereksinimleri öne çıkmaktadır.

Yaşlıların heterojen bir grup olduğu bilinmektedir. Dolayısıyla, yaşlılık döneminde sağlık ve diğer gereksinimler de birbirinden farklılaşabilmektedir. Bütün bu nedenlerle yaşlılar için planların ve programların bireylerin ve toplumun öncelikli gereksinimlerine göre yapılması uygun olur.

Bu yazı kapsamında; yaşlanınca nelerin değiştiği ve özellikle sağlık/hastalık durumlarındaki farklılıklar incelenmiştir. Bu inceleme sırasında yaşlılığın kavramsal olarak tanımı, geçmişten bugüne kavramlardaki değişimler, sağlık/hastalık konularında öne çıkanlar, sağlıklı bir yaşlanma için öneriler üzerinde durulmuştur. Hastalık yükünün azaltılmasının yanı sıra yaşam kalitesinin iyileştirilmesi için koruyucu ve sağlı̆̆ın korunması yaklaşımlarının geliştirilmesi önerilmektedir.

Anahtar sözcükler: Yaşlı, Sağlık, Değişim, Gereksinim, Sağlığın Geliştirilmesi

${ }^{1}$ Prof. Dr., Hacettepe Üniversitesi, Tıp Fakültesi, Halk Sağlı̆̆ı Anabilim Dalı

${ }^{2}$ Dr., Tıpta Uzmanlık Öğrencisi

${ }^{3}$ Dr., Tıpta Uzmanlık Öğrencisi

SAD / JSR

Cilt / Volume 21 Sayı / Number 2 


\title{
EVALUATION OF HEALTH/DISEASE PROFILES OF THE AGED PEOPLE IN TERMS OF PUBLIC HEALTH
}

\begin{abstract}
Aging period, also known to be the periods of "wisdom" and "second childhood" is a very important era of life in which major physiologic, psychologic, sociologic changes occur. To survive a healthy life in older ages, one should start to internalize preventive behaviors in the very early stages of life. As there is an increasing trend in aged population in number both in the world and in Turkey, the need for system-based changes about aging in all societies seem to be a high priority.
\end{abstract}

It is known that older people are heterogeneous groups. Consequently, health and disease related needs are expected to differentiate in older ages. Due to all these reasons, plans and programs for older ages are recommended to be done focusing to the prior needs of the individuals and societies.

In this paper, changes and the health/disease profiles when one ages have been studied. During this work, definition of aging, conceptual changes starting from the past, priorities about health and disease concern(s) and recommendations about healthy aging have been investigated. Preventive methods and health promotion strategies are recommended to be widened to lessen the burden of diseases as well as to improve quality of life in older ages.

Key words: Aged, Health, Change, Need(s), Health Promotion 


\section{GİRIŞ}

Yaşl11ık dönemi sağlık, sosyal, ekonomik açılardan farklı gereksinimlerin ortaya çıktığı bir dönemdir. Yaşın ilerlemesiyle bireyler ve toplumlar çeşitli değişim süreçlerini yaşarlar. Toplumların "yaş" açısından değişimi için doğum, ölüm ve göç gibi yaşamsal olayların belirleyici olduğu bilinmektedir. Bir başka ifadeyle, toplumların yaşlanma sürecini anlayabilmek için demografik ve epidemiyolojik geçişin (değişimin) iyi anlaşılması gerekmektedir. Sosyo-ekonomik gelişime paralel olarak toplumlar yüksek doğurganlık ve ölüm hızlarından düşük doğurganlık ve ölüm hızlarına doğru bir geçiş eğilimindedirler. Demografik değişim ise genç yaşlarda mortalite (ölüm) hızındaki düşme ile başlar. Doğurganlık hızı yüksektir, nüfus artış hızı yüksektir, nüfus gençtir. Bunu izleyen aşamalarda doğurganlık hızı düşer, nüfus artış hızı düşer ve toplum yaşlanır. Daha sonraları da ilerleyen yaşlarda da ölüm hızı düşer, nüfus yaşlanmaya devam eder. Epidemiyolojik geçiş denildiğinde ise toplumda ölümlerin nedenlerinin bulaşıcı hastalıklardan bulaşıcı olmayan hastalıklara doğru kayma eğiliminde olmasından bahsedilir (Martin, 2011, s.34-38).

Bir toplumda yaşlı nüfusun artması o toplumun pek çok açıdan "başarılı" bir toplum olarak kabul edilmesini de sağlamaktadır. Özellikle halk sağlığı, eğitim ve sosyal politikaların yaşlanan toplumlarda daha etkili olarak hayata geçirildiği belirtilmektedir (“UN”, 2008, s.3). Ancak bu gelişmiş ülkeler için geçerlidir çünkü gelişmiş ülkelerde yaşlanma 100 yıl sürerken Türkiye'de 30-40 yılda ve çok hızlı bir şekilde gerçekleşmiştir.

Bu yazı kapsamında tüm dünyada giderek artan yaşlı nüfus dikkate alınarak, yaşlıların sağlık ve hastalık durumları ile ilgili halk sağlı̆̆ bakış açısıyla bir değerlendirme yapılması amaçlanmıştır.

Normal yaşlanma sürecinin (yaş alma) ve yaşl1lıkta görülen hastalıklarla ilgili konuların geçmişten bugüne farklı şekillerde isimlendirildiği bilinmektedir. Örneğin, Aristotle, M.Ö. 367 yılında "başarılı yaşlanmaya vurgu yaparak" Eugeria sözcügünü kullanmıştır. Eu; iyilik hali ve Geria ise yaşlılığın tedavisi için 
kullanılan ifadeler olmuştur (Mulley, 2012, s.225). Selsus ve Galen Gerocomie sözcüğüyle yaşl1lı̆̆ın tedavisi ile ilgilenen bilime vurgu yapmışlardır (treatment of old age) (Mulley, 2012, s.225). Galen için yaşl11ığın “soğuk (cold)" ve "kuru (dry)" olarak (Morley, 2004, s.1133) algılandığının düşünülmesi yanlış olmaz.

Günümüze yaklaştıkça Metchnikoff'un gerontoloji sözcügünü yaşl1lık dönemi ile ilgili biyolojik, davranışsal ve sosyal bilimler anlamında kullanmıştır. Ignatz Leo Nascher, geriatrinin en önde gelen isimlerinden olup 1909 yılında Geriatri sözcüğünü ilk kez yaşl1lıkla ilgilenen tıp bilimi olarak tanımlamıştır (the medicine of old age). Dolayısıyla modern geriatrinin; geriatri sözcüğünün Nascher tarafindan kullanılmasıyla doğduğu da düşünülebilir. Geriatri biliminin tarihsel gelişiminde yaşlılığın teorilerini içeren biyolojik gerontoloji (biological gerontology), bireyin yaşamını uzatan başarılı yaşlanma (successful aging), yaşlanma ile belirtilerin nasıl değiştiğini ortaya koyan ve hasta ve yeti kaybı olan kişilerin bakımına öncelik veren klinik geriatri (clinical geriatrics) bilimi öne çıkmaktadır. Nascher, yaşlılığın ve ilgili hastalıkların tıpkı pediatri gibi tıpta "ayrı/farklı" bir yeri olması gerektiğine vurgu yapmıştır. Nascher aynı zamanda normal yaşlanma sürecini "patolojik" süreçlerden de ayırmıştır. Nascher'in çalışmalarının o dönemlerde “yaşlı ayrımcılığı” ile ilgili söylemleri olan Kanadalı William Osler'e karşıt tez de oluşturduğu bilinmektedir (Mulley, 2012, s.227).

Yaşlanmanın genetik etkisinin bütün etkileyen durumlar içinde $\% 25$ olduğu, çevresel etkinin ise $\% 50$ olduğu belirtilmektedir. Daha uzun yaşam/yaş ile birlikte (örneğin 90-100 yaş) genetik etkinin daha etkili olduğu ifade edilmektedir (Taffet, 2015).

Bilimin hücresel, fizyolojik, organ temelli ve genetik teorilerle açıklamaya çalıştığı yaşlılığ daha iyi anlamak için bazı tanımları bilmek yararlı olacaktır (Balcombe \& Sinclair, 2001, s.836-838). Bunlar; kronolojik yaş; bireyin doğumuyla, hatta doğumdan önce başlayan bir süreçtir. Değerlendirmesi/ölçmesi kolaydır. Kronolojik temelli değerlendirmeler sırasında uluslararası kurumlar farklı kategorileri 
kullanmaktadırlar. Örneğin, gelişmiş ülkeler yaşlılıkla ilgili olarak 65 yaş ve üzeri döneme vurgu yaparken, Birleşmiş Milletler çoğunlukla 60 yaş ve üzeri nüfusu kullanmaktadır (WHO, 2016; UN, 2008, s.3; UN, 2015, s.1). Bu tanımlara ek olarak; 100 yaşını doldurmuş kişiler için "asırlık (centenarian)" ve 110 yaşını doldurmuş kişiler için de "süperasırlık (supercentenarian)" kavramları kullanılmaktadır (Karahan, 2013, s.465). Biyolojik yaş; fiziksel bir hastalığın olmaması, fonksiyon ve bilişsel bir kaybın yaşanıp yaşanmadığı ile ilgilenir. Yaşamın ilerleyen yıllarında kronik hastalıkların sıklığında artış beklenir. Yaşa bağlı diğer durumlar yaşanabilir. Sosyal yaş; yaşın ilerlemesiyle birlikte bireylerin toplumdaki rolleri de değişmektedir. $\mathrm{Bu}$ kavram içerisinde toplumun yaş nedeniyle bireylere atfettiği rolleri işaret eder. Fonksiyonel yaş (functional age) ise; bireylerin kendi başına, bağımsız olarak yaşamını sürdürmesi için gerekli fonksiyonlarının varlığına vurgu yapan bir yaklaşımı kapsamaktadır (Morgan \& Kunkel, 2016, s.2).

Yaşlılık döneminin homojen bir grup olmadığı bilgisi oldukça önemli bir bilgidir. Dünya Sağlık Örgütü tarafından kullanılan 65 yaş ve üzeri kronolojik tanım kapsamındaki bu grup oldukça heterojen bir grup olup yaşamın her boyutunda farklılaşabilmektedirler (WHO Ageing and Health, 2015, s.7).

Yaşamın doğal bir süreci olan yaşl1lık sıklıkla sanatta da konu edilmektedir. William Shakespeare'in eserlerinde yaşlanma ile beraber fonksiyon kayıpları, yeti yitimi görülmektedir (Covey, 2000, s.171).

Yaşlanmanın fiziksel, sosyal, psikolojik/ruhsal ve toplumsal boyutları bulunmaktadır. Fiziksel yaşlanma (physical aging); insan organizmasının zamanla gelişimini, olgunlaşmasını ifade eder. Doğal/normal bir süreç olarak kabul edilir. Saçların beyazlaşması, deride kırışıklıkların meydana gelmesi gibi fiziksel değişimlere işaret eder. Ancak "normal” değişimi "normal olmayan (patolojik)" değişimden ayırt etmek gerekmektedir. Sosyal yaşlanma (social aging); yaşlanmaya toplumun şekillendirdiği çerçevede anlam vermek anlamı taşımaktadır. $\mathrm{Bu}$ bağlamda sosyal yaşlanmanın farklı yaşlarda toplumda nasıl davranacağımız, ne yapacağımız, vb. konularında beklentilerimizi ve varsayımlarımızı kapsamaktadır. Psikolojik/ruhsal yaşlanma (psychological aging); kişilikte, mental işlevsellikte benlikte oluşan 
değişimleri işaret eder. Bu kategoride bilişsel işlevlerdeki gerilemenin tek nedeninin yaşlanma olmadığına da vurgu yapılmaktadır. Toplumsal yaşlanma (societal aging) da toplumlarda yaşlı nüfusun toplam nüfus içindeki payında artma ile birlikte demografik, yapısal ve kültürel değişimler olarak tanımlanır. Bu değişim bireyi, aileyi, kurumsal yapıları, çalışma ortamını, vb. yakından etkiler (Morgan \& Kunkel, 2016, s.3).

\section{DÜNYADA VE TÜRKİYE'DE YAŞLI NÜFUSA DAİR DEĞİŞIMLER}

Dünyada her ay 1,2 milyon kişinin yaşlı nüfusa dahil olduğu ifade edilmektedir. Bu büyümenin dünya nüfusunun artma hızının iki katı bir hızda olduğu bilinmektedir (Morgan ve Kunkel, 2016, s.1).

Dünyada 2015 ve 2050 yılları arasında 60 yaş ve üzeri nüfusun \%12'den \%22'ye yükselmesi beklenmektedir. Sayının 2050 yılında iki milyara ulaşması ve aynı yıl için yapılan tahminlere göre yaşlıların \%80'inin az gelişmiş ve gelişmekte olan toplumlarda yaşayacakları tahmin edilmektedir. Dolayısıla bu kategorideki ülkelerin özellikle sistemleri açısından zorlukları olacağı öngörülmektedir (WHO Ageing and Health, 2015).

Yaşlanan toplumların da zaman içinde daha da yaşlandıkları görülmektedir. Özellikle 80 yaş ve üzeri yaşlıların artma eğilimlerindeki yükseklik dikkat çekmektedir. Bu grup her yıl \%3,5 artış göstermektedir. Yüzyılın ortasında yaklaşık yaşlı her beş kişiden birisinin (\%19) 80 yaş ve üzerinde olacağı beklenmektedir (UN, 2001). Bu sayı da mevcut durumun üç katına denk gelmektedir (UN, 2013, s.3).

Türkiye İstatistik Kurumu (TÜIK) verilerine göre, ülkemizde 1935 y1lında \%3,9 olan yaşlı nüfusun toplam nüfus içindeki payı 2017 yılında \%8,5 olmuştur. Ülkemizde toplam nüfus 2017 y1lında 80810525 ve 65 yaş ve üzeri nüfus da 6895 385'tir (TÜİK, 2017). Bu rakamlar göz önüne alındığında; Türkiye'deki yaşlı nüfusun dünyadaki bazı ülkelerin toplam nüfusundan daha fazla olduğunu hatırlamakta yarar bulunmaktadır. Örneğin Dünya Sağlık Örgütü 2015 yılı rakamlarına göre Norveç’in nüfusu 5,211,000 olarak kayıtlıdır (WHO Norway, 2015). Ya da Uruguay'ın aynı y1l nüfusu 3,432,000 olarak belirtilmektedir (WHO Uruguay, 2015). Örnekler artırılabilir.

$\mathrm{SAD} / \mathrm{JSR}$

Cilt / Volume 21 Sayı / Number 2 
Grafik 1'de 1935 ve 2017 yılları arasında nüfustaki değiş̧im görülmektedir (TÜiK, 2017). Bu değerlere göre Türkiye'de de 1990'lı yıllardan bu yana eğimin yukarı doğru bir ivmesi olduğu görülmektedir. Bir başka ifadeyle, yaşlı nüfus 1990'lı yıllardan bu yana daha önceki dönemlere göre daha hızlı bir artış göstermiştir. $\mathrm{Bu}$ değerlendirmenin sadece 65 yaş ve üzeri nüfusu dikkate alan "kronolojik" bir değerlendirme olduğu unutulmamalıdır.

Nüfusun yaşlanması ile ilgili bilgi veren göstergelerden bir diğeri ise ortanca yaştır. Türkiye'de ortanca yaş 2013 yılında 30,4 iken 2017 yılında 31,7 olmuştur. Nüfus projeksiyonlarına göre yapılan öngörülerde, ortanca yaşın 2030 yılında 35,6, 2060 yılında 42,3 ve 2080 y1lında 45 olacağ 1 tahmin edilmektedir (TÜíK, 2017). Ayrıca doğuşta beklenen yaşam süresi Türkiye geneli için 78 yıl, erkekler için 75,3 yıl ve kadınlar için 80,7 yıl olarak hesaplanmıştır. Genel olarak kadınlar erkeklerden daha uzun süre yaşamakta olup, doğuşta beklenen yaşam süresi farkı 5,4 yıldır (TÜíK, 2017).

\section{Yüzde}

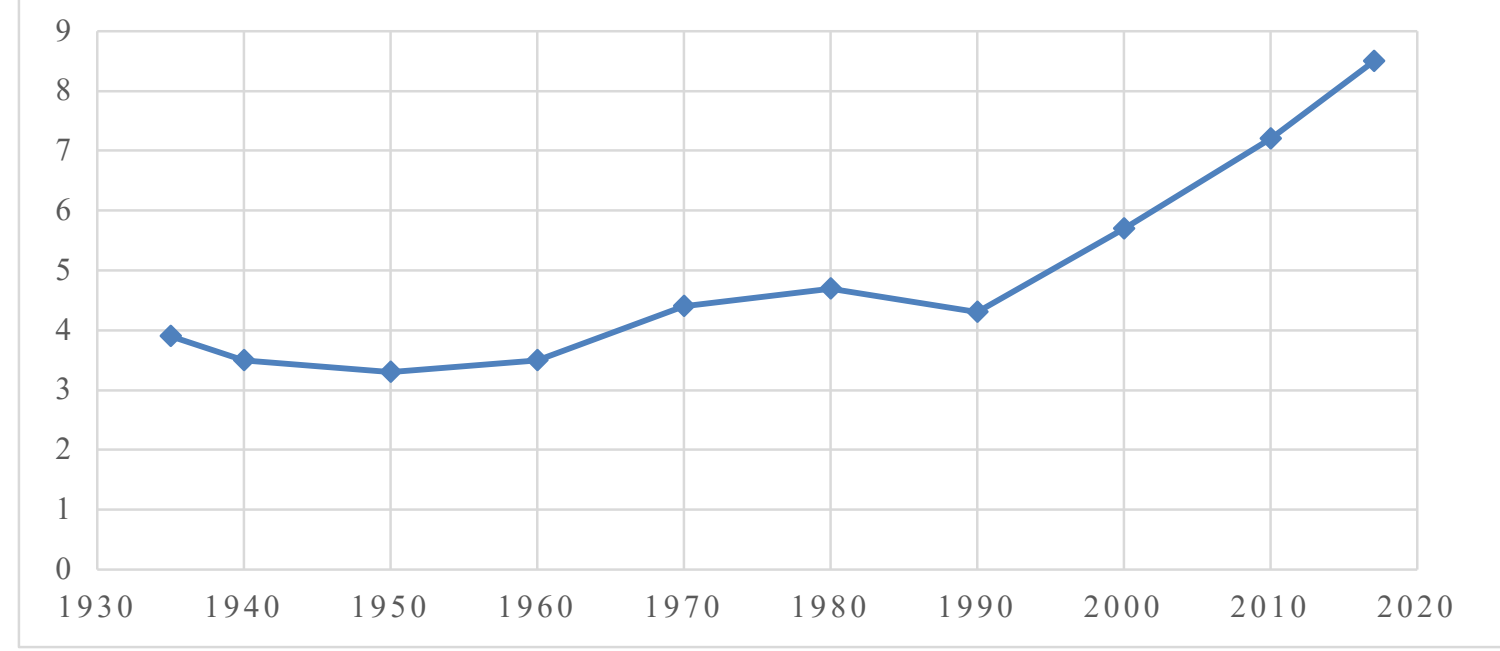

Şekil 1. Türkiye’de Yıllara Göre Yaşlı Nüfusun Toplam Nüfus İçindeki Payındaki Değişim (1935-2017)

Kaynak: TÜİK, 2017.

$\mathrm{SAD} / \mathrm{JSR}$

Cilt / Volume 21 Sayı / Number 2 


\section{YAŞLILIK DÖNEMINDE ÖNE ÇIKAN SAĞLIK SORUNLARI}

Yaşlanma ile birlikte kronik ve dejeneratif hastalıkların sıklığında artma eğilimi olduğu, ölümlerin ise metabolik disfonksiyon ve kanser nedenli beklendiği belirtilmektedir (Frankenberg \& Thomas, 2011, s.87).

Yaşl11ık döneminde çoğunlukla birden fazla hastalık birlikte görülmektedir (comorbidity). Komorbiditenin yaşlılar için hastane yatışı ve ölüm açısından bir risk olduğu ifade edilmektedir. Komorbiditesi olan hastalar sağlık hizmetlerini diğer gruplar göre daha sık kullanmaktadırlar (Vetrano vd., 2015, s.66).

Amerika'da CDC verilerine göre yaşlı bireylerin \%80'inin en az bir ve \%50'sinin en az iki kronik hastalığ 1 bulunmaktadır (Shah \& Hajyar, 2012, s.173).

Küresel olarak sık görülen kronik hastalıkları arasında; kalp hastalıkları, hipertansiyon, inme, astım, kronik bronşit-amfizem, kanser, diabetes mellitus, artrit yer almaktadır (Morgan \& Kunkel, 2016, s.20).

Yaşl11ık döneminde yaşa bağlı olarak sık görülen, birden fazla faktöre bağlı olarak gelişen, fonksiyon (işlev) kaybı ve/veya olumsuz sonuçlara yol açan hastalık ve durumlar "geriatrik sendromlar" olarak da tanımlanmaktadır. Asya Pasifik ülkelerinde yapılan çalışmada; bası yaraları, idrar tutamama, düşme, fonksiyon kayıpları, uyku sorunları/bozuklukları, bilişsel fonksiyonlarda gerileme, deliryum, malnütrisyon, ağrının da içinde bulunduğu "geriatrik sendromlar" tedavi edilebilir durumlar olarak belirtilmiştir (Wu, Chang \& Chen, 2012, s.14-15; Won vd., 2013, s.565).

Türkiye' de yaşlıların ölüm nedenleri incelendiğinde 2016 yılında ölümlerin \%45,6'sının dolaşım sistemi hastalıkları nedeniyle, \%16,3'ünün iyi huylu ve kötü huylu tümörler nedeniyle, \%13,9'unun ise solunum sistemi hastalıkları nedeniyle olduğu görülmektedir (TÜİK, 2017). 


\section{SAĞLIKLI YAŞLANMA VE MEVCUT SORUNLARIN ÇÖZÜMÜ İÇİN ÖNERİLER}

Bütün bu açıklamalardan sonra sağlıklı yaşlanma tanımını da hatırlamakta yarar bulunmaktadır. Sağlıklı yaşlanma; fiziksel çevrenin bireylerin sağlık ve iyilik halini sürdürmelerini sağlayan tutum ve davranışlarını desteklediğinde, sağlık hizmetleri ve toplumsal programların hastalıkların bireysel fonksiyon ve kapasiteye olan etkilerini en aza indiren nitelikte olduğunda sağlanabilmektedir (Satariano vd., 2012, s.1508). Dolayısıyla, sağlıklı yaşlanabilmek aslında çok geniş bir bakış açısına sahip olmayı gerektirmektedir. Sağlıklı yaşlanma vurgusu içinde sağlığın belirleyicileri, bireysel ve çevresel koşullara dikkat çekilmektedir. Sağlıklı yaşlanmayı önceleyen bir toplumda yaşlılık döneminde öne çıkan sorunların bilinmesinde yarar bulunmaktadır. Sağlıklı yaşlanma için “bütün politikalarda sağlık” vurgusu öne çıkarılmalıdır. Bu yaklaşım Helsinki’ de yapılan uluslararası sağlığın geliştirilmesi konferansında dünya kamuoyu ile paylaşılmıştır (WHO Conference on Health Promotion Helsinki, 2013).

Sağlıklı yaşlanma ile ilgili önleyici çevresel ve bireysel düzenlemeler yapılırken yaşlılık döneminde var olan sağlık sorunlarına da eşgüdüm içinde çözümler üretmek gerekir. Yaşl1lık döneminde görülen sağlık sorunlarının çözümü için korunma, erken tanı/tedavi ve rehabilitasyon hizmetlerinin herkesin gereksinimini karşılayacak şekilde, kesintisiz ve ulaşılabilir olması gerekmektedir (Şekil 2). 


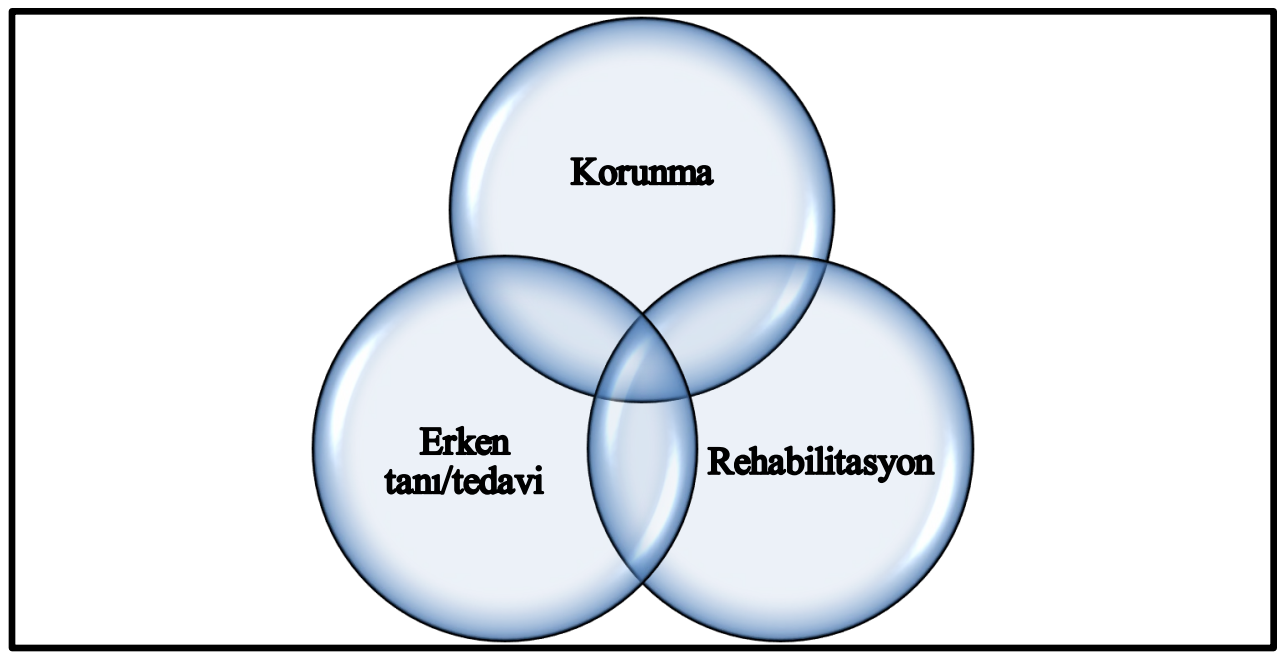

\section{Şekil 2. Yaşlılık Döneminde Görülen Sağlık Sorunlarının Çözümü İçin Entegre Yaklaşım}

Korunma denildiğinde hastalıkların oluşumunun önlenmesi anlaşılmalıdır. Bu başlıkta özellikle hastalıkları oluşturan risklerle mücadele önem kazanır. Yaşamın tamamı için geçerli olan başlıca yaklaşımlar aşağıda sıralanmıştır (Aslan, 2012, s.26; Gökçe Kutsal vd., 2015, s.83-84):

- Tütün kullanımından uzak bir yaşam

- Fizik aktivite

- Stresle uygun yöntemlerle baş edebilme

- Güneşin zararlı etkilerinden korunma

- Düzenli ve yeterli uyku

- Aşılama/bağışıklama hizmetleri

Davranış değişikliği gerektiren aşağıda da açıklanan bu adımlar yaşlılık döneminde sık görülen, hastalık ve ölümle sonuçlanan durumlarla karşılaşma riskini azaltmaktadır (Aslan, 2012, s.28):

$\mathrm{SAD} /$ JSR

Cilt / Volume 21 Sayı / Number 2 
Yeterli ve dengeli beslenme yaşl1lık dönemi için de son derece önemlidir. Öğün atlanmaması, besin çeşitliliği, her besin grubundan denge içinde tüketim gibi genel yaklaşımlar herhangi bir özel durum/hastalık varlığında farklılaşabilir. Böylesi bir durumda mutlaka hekim ve diğer sağlık profesyonelleri ile iletişim önerilmektedir (Aslan, 2011, s.134).

Altmış beş yaş ve üzeri kişiler arasında tütün kullanma sıklığı diğer yaş gruplarına göre daha azdır. Bununla birlikte, tütün kullanımı yaştan bağımsız olarak her zaman bırakılması gereken bir davranıştır. Yaşlılık döneminde de bireyler diğer yaş gruplarında olduğu gibi pasif etkilenimden korunmalıdır.

Orta düzey fiziksel aktivite süresi DSÖ tarafından önerildiği üzere haftada 150 dakikadır. Önerileri yerine getirmeyen bir yaşlının düşme ve sağlık açısından diğer riskleri önerileri yerine getiren bir yaşlıya göre daha fazladır (Jefferis vd., 2014, s.4). Ankara'da bir huzurevinde 2014 yılında yapılan bir çalışmaya göre son bir yıl içinde erkeklerin \%47,5'inin ve kadınların da \%56'sının düştüğü saptanmıştır (Kibar, Aslan, Gökçe Kutsal \& Karakoç, 2015, s.27). Dolayısıyla oldukça sık görülen düşmelerin de içinde olduğu hareketsiz yaşam sorununun çözülmesi için fiziksel aktivitenin mutlaka yaşlılar tarafindan düzenli olarak yapılmasının sağlanması gerekir. Yürüme, bahçe işleri, ev işleri, bisiklete binme, yüzme, dans etme yaşlılık döneminde yapılabilecek bedensel etkinlik türleri arasındadır. Bu dönemde kas gücünü artıran ve dengeyi sağlayan/geliştiren hareket türlerinin de yapılması sağlık açısından yararlıdır (WHO, Physical activity, 2015, s.7; Şahin, 2005, s.78).

Aşılama/bağışıklama yaşlılık döneminde bulaşıcı hastalıklardan korunmak amacıyla önerilmektedir. Bu dönemde pnömoni, grip aşıları hekim danışmanlığında yaptırılmalıdır. Özel bir durum olduğunda da ek aşıların yapılması gerekmektedir.

Yukarıdaki önerilere ek olarak yaşlıların kaza ve yaralanmalardan korunabilmeleri için de özel önlemlere gereksinim bulunmaktadır. Bu önlem ve düzenlemeler ev içinde ve ev dışında alınmalıdır. Ev içinde kayan 
(1slak) zeminlerin olmaması, düşmeye yol açacak kablo, halı, vb. olmaması, tuvalet ve banyolarda tutamak yapılması, trabzanların düşmeyi önleyecek şekilde yapılması, vb. ev içi önlemlerin bazılarıdır. Ev dışının inşası, düzenlemesi de yaşlıların yaşamlarını engellemeyen tarzda olmalıdır (Erkılıç, Aydoğdu, Aslan \& Gökçe Kutsal, 2006, s.9-31).

Sağlığın "bedenen, ruhen ve sosyal açıdan tam bir iyilik hali” olarak bilinen evrensel tanımı dikkate alındığında, özellikle sosyal iyilik halinin sağlanması ve sürdürülmesi için sağlığın sosyal belirleyicilerinin iyileştirilmesi gerekmektedir. Sağlığın belirleyicileri denildiğinde ise barınma, beslenme, sosyo-ekonomik koşullar, kültür, toplumsal değerler, toplumsal cinsiyet, vb. konular anlaş1lmalıdır (Aslan, 2012, s.26). Ad1 geçen koşulların herhangi birisinin eksikliğinde sağlıklı olma halinin sürdürülmesi olanaksız hale gelebilir. Kırılganlığın (frailty) arttığı yaşlılık döneminde ise bu tür olumsuzluklardan daha ağır olarak etkilenildiği bilinmektedir (Liu vd., 2018, s 1). Sosyal sağlığın sürdürülmesi için son dönemlerde daha çok gündemde olan bir konu da yaşlı bireylerin sosyal ilişkilerini sürdürdükleri, geliştirdikleri ortamların varlığının önemi olmuştur. Sosyal sağlığın fiziksel ve ruhsal sağlık için destekleyici rolü olduğu literatürde yaygın olarak kabul edilmektedir (Fişek, 1985, s.1-2). Mental/zihinsel sağlığın korunması için ise bilişsel işlevlerin ve egzersizlerin sürekli olarak yapılması önerilmektedir. Böylelikle Alzheimer gibi demans tiplerinin önlendiğine ilişkin veriler bulunmaktadır (CDC, 2015).

Yaşlılık döneminde hastalıkların erken tanısı ve tedavisi yaşam süresini uzatan ve yaşam kalitesini artıran bir boyuttadır. Bu tür hizmetlere ulaşım tanı ve tedavi hizmetlerinin herkes için eşit ve ulaşılabilir olması ile yakından ilişkilidir. Tarama programları, düzenli sağlık kontrolleri yaşlılık dönemindeki hastalıkların erken tespitini sağlamaktadır. Belirli yaşlarda/dönemlerde belirli tetkiklerin/kontrollerin yapılması önerilmektedir (Dağdelen, 2011, s.15):

- Hekimlerin önerdiği takvimde kan değerleri takibi

$\mathrm{SAD} / \mathrm{JSR}$

Cilt / Volume 21 Sayı / Number 2 
- Sık görülen hastalıklar (hipertansiyon, diabetes mellitus, kalp hastalığı, işitme ve görme açısından yeti kaybı, osteoporoz vb) açısından düzenli kontrol

- Kanser taramaları (meme, vb)

Olağan kontrol programları birey açısından riskli bir durum varlığında farklılaşabilir. Örneğin bireyin yaşam tarzında herhangi bir risk var ise hekimler daha farklı bir izleme/değerlendirme programı uygulayabilmektedir. Pek çok hastalıkta bilinen olguların, bilinmeyen olgulardan sayıca çok az olması erken tanının önemine işaret etmektedir. Bu anlatım buzdağı olgusu kavramını akla getirmektedir. Yukarıda yazılı olanlara ek olarak yaşlılık döneminde kötü muamele, ihmal, istismar olgularının da görüldügü, istenmeyen bütün bu durumların önlenebileceği, önlenemediğinde ise tanı, tedavi ve rehabilitasyon olanaklarının varlığı unutulmamalıdır (Aslan, 2015, s.81-82).

Hastalıkların erken tanı ve tedavisinin yapılamadığ 1 durumlarda da yapılacaklar vardır. Rehabilitasyon (esenlendirme) olarak adlandırılan bu hizmetler yeti yitimi ve işgücü kaybına uğrayan bireylerin yaşamlarında herhangi bir engel ile karşılaşmalarını önlemekte ve yaşam kalitesinin gerilemesini engellemektedir (Fişek, 1985, s.6).

Hekimler yaşlı başvuran/hastalarla karşılaştıklarında yaşlılarda görülen hastalıkların semptomlarının yaşlı olmayan bireylerin semptomlarından farklı şekilde görülebileceğini hatırlamalıdır. Buna ek olarak, yaşlıların hastalığa özel olmayan bulguları, hasta-hekim iletişimi sırasında yaşlılar tarafından çoğunlukla belirtilmeyen ve yaşlılığın doğal süreci olarak kabul edilen şikayet ve bulgular, birden fazla hastalığın görülme olasılığının yüksek olması gibi durumlar da hekimlerin dikkat etmesi gereken konular arasındadır. Dolayısıyla, öykü alırken, muayene ederken, tetkik için yönlendirirken ve tedavi ile ilgili kararını verirken hekim yaşl11ığa özel bütün bu durumları göz önünde bulundurmalıdır (Gökçe Kutsal, 2015, s.30). 
Yukarıda her ne kadar hekim rolüne vurgu yapılmış olsa da yaşlılara yönelik sunulan sağlık ve diğer hizmetlerin bir ekip hizmeti yaklaşımını gerektirdiği unutulmamalıdır. Hekim, hemşire, psikolog, sosyal hizmet uzmanı, sosyolog, diyetisyen, gerontolog, fizyoterapist, bu geniş ekibin temel elemanları arasındadır. Sağlık dışındaki hizmetler için de geniş bir ekip anlayışına ihtiyaç vardır. Yerel yönetimler, medya, eğitim sektörü, kamunun pek çok kurum ve kuruluşu, ulusal ve uluslararası sivil toplum örgütleri bu ekibin dinamik üyeleridir.

Sonuç olarak yaşlıların sağlığının korunması ve geliştirilmesi son derece önem taşımaktadır. Bunun sağlanabilmesi için de halk sağlığı bakış açısıyla öncelikle yaşlıların sağlık ve hastalık durumlarının iyi anlaşılması ve toplumsal müdahalelerin bu çerçevede yapılması gereklidir. 


\section{SUMMARY}

Aging period, also known to be the periods of "wisdom" and "second childhood" is a very important era of life in which major physiologic, psychologic, sociologic changes occur. To survive a healthy life in older ages, one should start to internalize preventive behaviors in the very early stages of life. However, healthy aging in not only an individual issue, but a system priority as well. As there is an increasing trend in aged population in number both in the world and in Turkey, the need for system-based changes about aging in all societies seem to be a high priority.

It is known that older people are heterogeneous groups. The fact that time interval starting from almost 60 years of age and ends when one dies is long, varieties in the interaction dynamics between the determinants of health and the individuals' characteristics, differences in health/disease profiles are among major causes of the heterogeneity. Consequently, health and disease related needs are expected to differentiate in older ages. Due to all these reasons, plans and programs for older ages are recommended to be done focusing to the prior needs of the individuals and societies.

In this paper, changes and the health/disease profiles when one ages have been studied. During this work, definition of aging, conceptual changes starting from the past, priorities about health and disease concern(s) and recommendations about healthy aging have been investigated. When one ages, several diseases are expected increase in frequency due to the functional capacity decline. Preventive methods and health promotion strategies are recommended to be widened to lessen the burden of diseases as well as to improve quality of life in older ages.

$\mathrm{SAD} / \mathrm{JSR}$

Cilt / Volume 21 Sayı / Number 2 


\section{KAYNAKLAR}

Aslan, D. (2015). Halk Sağlı̆ğ Bakış Açısıyla Yaşlılara Yönelik İstismar ve İhmal. Sürekli Tip Eğitimi Dergisi, 24(2), 79-82. Erişim Adresi: http://www.ttb.org.tr/STED/images/files/dergi/2015/2.pdf. (Erişim Tarihi: 23.12.2016)

Aslan, D. (2012). Yaşl1lık Döneminde Koruyucu Hekimlik. Türkiye Klinikleri Aile Hekimliği Özel Sayısı, 3(6), 25-9. Erişim Adresi: http://www.turkiyeklinikleri.com/article/en-yaslilik-donemindekoruyucu-hekimlik-64337.html. (Erişim Tarihi: 07.11.2017)

Aslan, D. (2011). Yaşl11ık Döneminde Beslenme: Hekim Perspektifi. Hekimleri İçin Temel Geriatri (s. 133139) içinde. Ankara: Ankara Tabip Odası ve Türk Geriatri Derneği yayınları, (ISBN: 978-6055867-41-6).

Balcombe, N.R. and Sinclair, A. (2001). Ageing: Definitions, Mechanisms and the Magnitude of the Problem. Best Practice \& Research Clinical Gastroenterology, 15(6), 835-49. doi:10.1053/bega.2001.0244

Centers for Disease Control (CDC) (2015). Alzheimer's Disease. Erişim Adresi: http://www.cdc.gov/aging/aginginfo/alzheimers.htm (Erişim Tarihi: 22.12.2015)

Covey, H. (2000). Shakespeare on Old Age and Disability. The International Journal of Aging and Human Development, 50(3), 169-83.

Dağdelen, S. (2011). Yaşı Hastanın Değerlendirilmesi ve Periyodik Sağlık Kontrolü. Hekimleri Iç̧in Temel Geriatri (s. 15) içinde. Ankara: Ankara Tabip Odası ve Türk Geriatri Derneği yayınları, (ISBN: 978-605-5867-41-6).

Erkılıç, M., Aydoğdu, F., Aslan, D., Gökçe Kutsal, Y. (2006). Yaşlının Evi ve Çevresi-Yaşlılık Dönemi İçin Uygun Çevre Koşulları Nasıl Düzenlenmelidir? Ankara: Türk Geriatri Derneği Yayınları, (ISBN 975-92150-1-2).

Fişek, N. (1985). Halk Sağlı̆̆ına Giriş. (s. 6,76). Ankara: Hacettepe Üniversitesi Tıp Fakültesi Yayınları.

Frankenberg, E. and Thomas, D. (2011). Global Aging. Handbook of Aging and Social Sciences içinde (p: 83-9). Binstock R. H., George L.K. (Eds). 7th Ed. Elsevier Publications. (ISBN:978-0-12-380880$6)$. 
Gökçe Kutsal, Y., Kabaroglu, C., Aslan, D., Sengelen, M., Eyigor, S., Cangoz, B. (2015). Gerontology in Turkey. Advances in Gerontology, 28 (1-Suppl.), 80-99. Retrieved from http://citeseerx.ist.psu.edu/viewdoc/download?doi=10.1.1.718.7861\&rep=rep1\&type=pdf\#page= $\underline{80 .}$

Gökçe Kutsal, Y. (2015). Hekim Gözüyle Yaşlılık Olgusu ve Algısı. Geriatrik Bilimler Kitabı, s. 24-35. Hacettepe Üniversitesi GEBAM Yayınları.

Jefferis, B.J., Iliffe, S., Kendrick, D., Kerse, N., Trost, Sç, Lennon, L., Sartini, C., Morris, R.W., Wannamethee, S.G., Whincup, P.H. (2014). How Are Falls and Fear of Falling Associated with Objectively Measured Physical Activity in A Cohort of Community-Dwelling Older Men? BMC Geriatrics, 14(1), 114. doi:10.1186/1471-2318-14-114.

Karahan, A.Y., (2013). Bir Olgu Eşliğinde Süperasırlık Kavramı. Turkish Journal of Geriatrics/Türk Geriatri Dergisi, $\quad$ 16(4), 464-6. Erişim adresi: http://eds.b.ebscohost.com/eds/pdfviewer/pdfviewer?vid=3\&sid=d1b6d1d6-31b4-467f-a378cded97f801a5\%40sessionmgr104. (Erişim Tarihi: 21.04.2017)

Kibar, E., Aslan, D., Gökçe Kutsal, Y., Karakoç, Y. (2015). Ankara’da Bir Kurumda Yaşayan Yaşlılar Arasında Düşme Sıklığı, Risk Faktörleri ve Korunmaya İlişkin Yaklaşımlar. TAF Preventive Medicine Bulletin, $\quad$ 14(1), 23-32. Erişim adresi: http://eds.a.ebscohost.com/eds/pdfviewer/pdfviewer?vid=1\&sid=14bee523-0040-4d81-a6fa4829d7be6551\%40sessionmgr4008. (Erişim Tarihi: 21.12.2016)

Liu, L. K., Lee, W. J., Wu, Y. H., Hwang, A. C., Lin, M. H., Shimada, H., Peng, L. N., Loh, C. H., Arai, H., Chen, L. K. (2018). Cognitive Frailty and Its Association with All-Cause Mortality among Community-Dwelling Older Adults in Taiwan: Results from I-Lan Longitudinal Aging Study. Rejuvenation Research.doi:10.1089/rej.2017.2038

Martin, L.G., (2011). Demography and Aging. Handbook of Aging and Social Sciences. Binstock, R.H., George, L.K. (Eds). Seventh Ed. Elsevier Publications, pp 33-45. (ISBN: 978-0-12-380880-6).

Morgan, L.A. and Kunkel, S.R. (2016). Aging and Society. Aging, Society and the Life Course. Springer Publishing Company. Fifth Ed, p 1-22. 
Morley, J. E. (2004). A Brief History of Geriatrics. The Journals of Gerontology Series A: Biological Sciences and Medical Sciences, 59(11), 1132-1152. doi:10.1093/gerona/59.11.1132

Mulley, G., (2012). A History of Geriatrics and Gerontology. European Geriatric Medicine, 3(4), 225-227. doi:10.1016/j.eurger. 2012.06.007

Satariano, W. A., Guralnik, J. M., Jackson, R. J., Marottoli, R. A., Phelan, E. A., \& Prohaska, T. R. (2012). Mobility and Aging: New Directions for Public Health Action. American Journal of Public Health, 102(8), 1508-1515. doi:10.2105/AJPH.2011.300631

Şahin, G. (2005). Yaşl11ık ve Egzersiz. Turkiye Klinikleri Journal of Internal Medical Sciences, 1(27), 7680. Erişim Adresi: http://www.turkiyeklinikleri.com/article/en-yaslilik-ve-egzersiz-36354.html. (Erişim Tarihi: 21.04.2017)

Shah B.M. and Hajyar E.R. (2012). Polypharmacy, Adverse Drug Reactions, and Geriatric Syndromes. Clinics in Geriatric Medicine, 28(2), 173-86. doi: 10.1016/j.cger.2012.01.002

Taffet, G.E. (2015). Normal Aging. Schmader K. E. (Section Ed.), Sokol H.N. (Deputy Ed). Up to Date. Retrieved from http://www.uptodate.com/contents/normalaging? source $=$ machineLearning\&search $=$ aging \&selectedTitle $=1 \% 7 \mathrm{E} 150 \&$ sectionRank $=1 \&$ ancho $\underline{\mathrm{r}=\mathrm{H} 189995853 \# \mathrm{H} 189995853 .}$

Türkiye İstatistik Kurumu (TÜIK). Istatistiklerle Yaşlılar (2017). Erişim Adresi: http://www.tuik.gov.tr/PreHaberBultenleri.do?id=27595. (Erişim Tarihi: 20.4.2018)

United Nations, Department of Economic and Social Affairs, Population Division. (2015). World Population Ageing 2015 Report. (ST/ESA/SER.A/390). Retrieved from http://www.un.org/en/development/desa/population/publications/pdf/ageing/WPA2015_Report.p df.

United Nations (UN), Department of Economic and Social Affairs, Population Division. (2013). World Population Ageing 2013 Report. (ST/ESA/SER.A/348). Retrieved from http://www.un.org/en/development/desa/population/publications/ageing/WorldPopulationAgeing Report2013.shtml. 
United Nations (UN) Department of Economic and Social Affairs, Population Division. (May 2008). Guide to the National Implementation of the Madrid International Plan of Action on Ageing, p3. Retrieved from http://www.un.org/esa/socdev/ageing/documents/papers/guide.pdf.

United Nations (UN) Department of Economic and Social Affairs, Population Division. (2001). World Population Ageing: 1950-2050. Retrieved from http://www.un.org/esa/population/publications/worldageing19502050/.

Vetrano, D. L., Foebel, A. D., Marengoni, A., Brandi, V., Collamati, A., Heckman, G. A., and Onder, G. (2015). Chronic Diseases and Geriatric Syndromes: The Different Weight of Comorbidity. European Journal of Internal Medicine, 27, 62-67. doi:10.1016/j.ejim.2015.10.025.

Won, C.W, Yoo, H.J., Yu, S.H., Kim, C.O., Dumlao, L.C.I., Deviatsy, E., Rowland, J., Chang, H.H., Wang, J., Akishita, M., Tan, T.L., Lum, C., Prakash, O., (2013). Lists of Geriatric Syndromes in The Asian-Pacific Geriatric Societies. European Geriatric Medicine, 4(5), 335-338. doi: 10.1016/j.eurger.2013.07.005

World Health Organization (WHO). (2015). Ageing and Health. Retrived, Retrieved from http://www.who.int/mediacentre/factsheets/fs404/en/.

World Health Organization (WHO). (2016). Definition of Older or an Elderly Person. Retrieved from http://www.who.int/healthinfo/survey/ageingdefnolder/en/.

World Health Organization (WHO). (2015) Countries Norway. Retrieved from http://www.who.int/countries/nor/en/.

World Health Organization (WHO). (2015). Physical Activity and Older Adults. Retrieved from http://www.who.int/dietphysicalactivity/factsheet_olderadults/en/index.html.

World Health Organization (WHO). (2015). Countries Uruguay. Retrieved from http://www.who.int/countries/ury/en/.

World Health Organization (WHO). World Report on Aging and Health 2015. p 7. Retrieved from http://apps.who.int/iris/bitstream/10665/186463/1/9789240694811 eng.pdf?ua=1.

World Health Organization(WHO). (2013). The 8th Global Conference on Health Promotion. Helsinki. Retrieved from http://www.who.int/healthpromotion/conferences/8gchp/statement_2013/en/.

$\mathrm{SAD} / \mathrm{JSR}$

Cilt / Volume 21 Sayı / Number 2 
Wu, C.H., Chang, C.I., Chen. C.Y. (2012). Overview of Studies Related to Geriatric Syndrome in Taiwan. Journal of Clinical Gerontology \& Geriatrics,3(1), 14-20. doi: doi.org/10.1016/j.jcgg.2011.05.002. 